Revista Iberoamericana, Vol. LXXIV, Núm. 225, Octubre-Diciembre 2008, 1039-1057

\title{
MÁS ALLÁ DE LA HOMONORMATIVIDAD: INTIMIDADES ALTERNATIVAS EN EL CARIBE HISPANO ${ }^{1}$
}

\author{
POR \\ Yolanda Martínez-San Miguel \\ University of Pennsylvania
}

A Larry LaFountain-Stokes. Con afecto.

\section{HOMONORMATIVIDAD Y CARIBEÑIDAD}

Invocando el gesto de la iluminadora reflexión que Jane Gallop propone en su libro Anecdotal Theory, comienzo con una anécdota: "Dos mujeres -una de ellas delgada, alta, y de apariencia andrógina, la otra una femme bien femme- se están besando en un rincón medio oscuro de una discoteca gay muy popular en Puerto Rico. Una drag-queen, pensando que una de ellas es un hombre, interrumpe este momento íntimo para recordarles que a los heterosexuales no se les permite besarse en el 'safe space' del bar gay. Las dos mujeres se separan, y miran a la draga anonadadas, al mismo tiempo que la draga se da cuenta de su error. 'Pero yo soy una mujer', la buchita alta le dice. ‘Ay perdón, yo también’, la draga responde. Las tres se ríen. Todo el mundo está bien, de regreso a la comodidad del espacio que alberga y tolera todas las alteridades. Pero con esta escena aparentemente graciosa e inocente, hemos entrado al territorio de la homonormatividad (Anécdota compartida entre amigos, República Dominicana, junio de 2005). ${ }^{2}$

Me gustaría comenzar definiendo lo que entiendo por "homonormatividad", término acuñado por Lisa Duggan para referirse a una política que no cuestiona las instituciones heteronormativas, sino que las defiende y sostiene como un modo de oficializar e integrar a la comunidad gay en el resto de la sociedad. Algunos de los ejemplos de esta reorientación del movimiento gay hacia la derecha en los Estados Unidos son el privilegio que se le ha concedido a la consecución del matrimonio gay

1 Agradezco los comentarios y sugerencias bibliográficas de Lawrence LaFountain-Stokes, Ben Sifuentes-Jáuregui, Lázaro Lima y Celiany Rivera-Velázquez.

2 Este incidente refleja una política oficial, ya que conozco el caso de otra pareja heterosexual que fue expulsada de la discoteca como resultado de sus expresiones públicas de afecto dentro del establecimiento. 
y el argumento sobre el poder económico como un modo de justificar la protección de los derechos civiles y sociales de este sector. Esta discusión de la homonormatividad nos lleva a pensar el movimiento gay y lésbico en el contexto de otros movimientos de minorías -ya sea étnicas, raciales, sexuales, sociales o políticas- que han debatido la integración a la sociedad oficial o la lucha contra las prácticas de exclusión en la definición de sus agendas políticas. Adopto el término de Duggan, pero lo utilizo para referirme a la institucionalización de una identidad gay hegemónica que se puede convertir en una postura tan excluyente y opresiva como los discursos y prácticas heteronormativas. Uno de los resultados de esta institucionalización de lo homonormativo es que el tema de la libertad sexual resulta desplazado por una ansiedad de definir y visibilizar una identidad gay pública que ignora o condena a aquellos que retan el concepto de la monogamia o a quienes se sienten excluidos por un sistema genérico binario. ${ }^{3}$

El tema que me interesa abordar en este ensayo, sin embargo, no es la representación de los gestos represivos de las políticas de la identidad gay contemporánea. Propongo una intervención crítica que rearticula nuestra concepción de alteridad sexual, de modo que el deseo se convierte nuevamente en esa "perversidad polimorfa” que en el trabajo de Freud funciona como la pulsión desestabilizadora originaria en la constitución de una identidad (57). Utilizo como punto de partida dos intervenciones críticas que me parece que nos estimulan a trascender la (homo y hetero) normatividad y a recuperar el elemento políticamente radical en el que se fundamentan los estudios sobre las identidades queer. ${ }^{4}$ La primera es una escena medio traviesa en la que se detiene el estudioso puertorriqueño Rubén Ríos Ávila en su ensayo titulado "Rambling":

It was 20 years ago, on a hot Summer afternoon in Central Park. The Gay Parade had reached its final destination, we were tired and exhilarated. The march was over, the political speeches were over, our job was done and we were ready for some action. So, Grace Jones came out of a stretch limo and was hauled on top of the roof wearing black leather pants, spiked boots and impossibly hard nipples. Of course, she was singing I Need a Man, the gay anthem that year, and suddenly I felt that I needed

3 El tema de la visibilidad y las agendas políticas en la lucha por los derechos civiles de las minorías sexuales ha generado una gran variedad de debates. Algunos críticos también han cuestionado la narrativa del “coming out” como estrategia normativizante. Por ejemplo, José Quiroga, en la introducción a su libro Tropics of Desire, cuestiona esta hegemonía del "coming out narrative" en su análisis del uso de máscaras en la primera marcha de orgullo gay en Buenos Aires (1-29). Otros críticos, como Lawrence LaFountain-Stokes y Pablo E. Ben, problematizan esta estrategia de la identidad enmascarada como otra forma de invisibilizar la identidad gay en Latinoamérica.

4 Queer se puede utilizar como sinónimo de las identidades gay, lésbica, bisexual, y trans, pero en este ensayo utilizo la categoría para referirme a identidades que cuestionan discursos y prácticas (hetero y homo) normativas. 
one too. I drifted away from the place of the concert and started crossing, not to mention cruising, that most erotic area of the park known as The Rambles in order to get (I told myself) a breath of fresh air and also (the truth be said) a glimpse of fresh bodies, intermittently available, humid and glistening in the shade.

As I walked through this Victorian maze, pushing the bushes with a certain trepidation and feeling of confident anticipation, a "polemically persistent smell" as Carlota says in Quíntuples, distracted me. It smelled of lard and fried flour, of salted codfish. It was unmistakable: somebody was frying bacalaítos on Central Park. I could not help it: my nose took over against the wishes of my lower body. If it is true that the brain started out over a million years ago as an extension of the olfactory tissue which warned us of strangers and indicated where food was on our first nomadic forays, then I was experiencing a true primitive epiphany and as a result of it I no longer needed a man. I smelled, therefore I was, and I needed a bacalaíto. Or perhaps I wanted both. (311-12, mi énfasis)

En este texto, Ríos Ávila explora la intersección entre la identidad sexual y etno-nacional cuando es testigo de la confluencia del Desfile Gay y la celebración de la Noche de San Juan en Central Park. ${ }^{5}$ Me gustaría denominar esta escena como un momento perfectamente ambi-sexual y pati-bi-fuso. ${ }^{6}$ En esta escena, Ríos Ávila explora la colisión y tensión entre dos lugares de identificación igualmente seductores -la homosexualidad y la puertorriqueñidad-, lo que genera una instancia de incertidumbre (lo pati-bi-fuso) que culmina en una aceptación de dos pulsiones que no son ni homo ni heterosexuales (lo ambisexual). Este momento se describe físicamente como el desplazamiento de "los deseos de las partes inferiores del cuerpo" por la primitiva epifanía olfativa que está vinculada a la alimentación básica del cuerpo y su centro de operaciones, el cerebro. El olor prefigura el hambre que alude al

5 Adopto el término etno-nación, según lo proponen Ramón Grosfoguel, Frances Negrón-Muntaner y Chloé Georas en la introducción a Puerto Rican Jam: "Thus, it can be argued that to the extent that Puerto Ricans make political (territorial) claims on behalf of Puerto Ricans, Puerto Ricans constitute a national formation. At the same time, to the extent that a political claim is made on behalf of Puerto Ricans formally relinquishing state power, Puerto Ricans constitute a partially territorialized ethnic group (islanders). Since both tendencies not only coexist between groups but also simultaneously in social and subjective contexts, Puerto Ricans imagine themselves as an 'ethno-nation,' with different emphasis on both sides of the hyphen” (17). Me parece que esta noción nos permite hablar simultáneamente de la experiencia nacional caribeña según se articula en cada una de las islas del Caribe hispano, así como en los enclaves caribeños en ciudades estadounidenses.

${ }^{6}$ El concepto de ambisexual se lo debo a un alumno de una colega en Rutgers, que inventó esta palabra para referirse a un escritor bisexual. En mi texto, sin embargo, ambisexual se refiere a un sujeto cuya sexualidad se define en interacción con más de un objeto de deseo, y por lo tanto trasciende las identidades gay, straight y bisexual en sus definiciones más tradicionales. "Pati-bi-fuso" lo invento a partir del vocablo patidifuso, que significa "que se queda parado de asombro" (DRAE II:1548), y del juego de palabras "pato" (que se utiliza en el Caribe para referirse a los homosexuales) y "bisexual”, produciendo pati-bi-fuso. 
deseo sexual primigenio en su urgencia y significado, y con ello quedamos atrapados en el cortocircuito del cuerpo y sus pulsiones, en un espacio que está más allá de la identificación específicamente hetero u homosexual (Freud 45-50).

Al mismo tiempo, en el ensayo de Ríos Ávila se imbrica la celebración de liberación sexual de la marcha de orgullo gay en los rambles del Central Park con la celebración de la religiosidad popular boricua doblemente diasporizada en la celebración en el parque neoyorquino y en la práctica culinaria boricua, en la que confluyen influencias africanas (la fritura) y europeas (el bacalao). La imbricación no cesa aquí, por otra parte, ya que no podemos ignorar que el sujeto que deambula por el parque central se divide entre su deseo por otro hombre y un bacalaíto. Si recordamos que en la cultura popular y el habla coloquial boricua es común referirse al órgano sexual femenino con nombres de diferentes pescados, y en particular del bacalao, el narrador del ensayo enuncia, más que una disyuntiva entre la nacionalidad y la sexualidad, su dilema entre ser boricua y gay como una pulsión paralela a un deseo localizado entre lo masculino y lo femenino. El hecho de que la reflexión concluya con una afirmación de que se necesitan ambos objetos de deseo es sumamente sugestiva. ¿Juego de palabras? ¿Equívoco involuntario? ¿O momento pati-bi-fuso fundacional de la identidad boricua insular y diaspórica?

La segunda intervención crítica que me gustaría invocar aquí proviene del libro del crítico cubano Lázaro Lima, titulado Latino Bodies: Crisis Identities in American Literary and Cultural Memory. En el cuarto capítulo del libro, Lima analiza la novela The Greatest Performance de Elías Miguel Muñoz. Sería pertinente recordar aquí que la novela de Muñoz narra la historia de dos exiliados cubanos, un hombre y una mujer, ambos homosexuales, que negocian en su afecto amistoso su etnicidad marginal y su alteridad sexual en la sociedad estadounidense durante la época de la pandemia del sida. Lima enfoca su comentario en la falta de imaginación de un crítico que "cannot conceive of a Cuban American lesbian who loves a deceased Cuban American 'homosexual' (Marbán's term) enough to provide an account of his revindication” (225). Lima añade:

\footnotetext{
The imbrication of Marito's life evoked by Rosita's writing creates a participatory narrative of queer allegiances between two characters who negotiate agency through united subjectivities. Rosita’s narrative locates Marito’s body as a site of queer gender negotiations that demonstrate the politicizing effects of the Latino body [...] Rosita's tapestry of love for Marito before, during, and after his death points to the importance of queer intimacy as necessary political action. [...] Rosita’s and Marito’s passion offers a reconfiguration of the familial; fleeing from their essentializing families they construct ties that are loving, contestatory, queer. (236-37)
}

Hay una escena en la novela en la que me parece que se ilustra claramente la dimensión queer de la pasión que comparten Marito y Rosita en su relación: 
[Marito says:] "I like it when it gets dark like this, Rosi [...] And I can see your face in chiaroscuro. Your body [...] so perfect in a swimming suit, baring your belly button [...] long legs, dark and firm, tanned to bronze [...] your eyes jet black, your short straight hair [...] My Cuban girl.”

"Your Cuban woman” [Rosita replies]. (137)

Lima comenta en su libro una serie de lecturas equivocadas del texto que es necesario mencionar aquí. Por una parte, le podemos imponer una lectura heteronormativa simplista al texto, explicando la relación entre Marito y Rosita como un vínculo platónico de una pareja que podría haber sido heterosexual. La otra posibilidad sería domesticar la evidente expresión de pasión presente en la narrativa para concebir el vínculo entre Marito y Rosita como un amor fraternal. Me parece interesante describir estas interpretaciones como equívocas, porque la novela insiste en la expresión física de una intimidad y afecto que une a Marito y Rosita en una pasión en la que se procesa su diferencia étnica, nacional y sexual. ${ }^{7}$ La lectura de Lima se fundamenta en el un concepto de "intimidad" que no es necesariamente sexual, pero que sí es profundamente afectivo y emocional, al punto de que existe entre Marito y Rosita una cercanía que es paralela a la atracción sexual. ${ }^{8} \mathrm{Al}$ mismo tiempo, la narrativa insiste en una relación que es íntimamente queer, sin ser específicamente homo- o hetero-sexual.

Me parece que Ríos Ávila y Lima invitan a sus lectores a explorar los límites de la homonormatividad, y a resistir la institucionalización de la identidad queer. En el trabajo de ambos el deseo homoerótico todavía es un factor clave en la definición de una perspectiva crítica que ilumina una nueva definición del Caribe vis-à-vis las definiciones latinoamericanas o latinas de la sexualidad, pero otra cosa ocupa el rol central en los discursos críticos y literarios que estoy citando aquí. En estos dos ensayos, la intervención crítica que se propone interroga los límites de las definiciones fijas de la identidad para explorar las intersecciones múltiples de deseos

7 De acuerdo con Karen Christian, la novela explora la correlación entre género sexual e identidad cultural: “The novel's gay and lesbian protagonists challenge the émigré community's paradigm of cultural identity by subverting these constructs of masculinity and femininity" (21). Yo me concentro más bien en la relación íntima entre Marito y Rosita como un modo de rebasar la oposición entre lo femenino/masculino, lesbianismo/homosexualidad, y cubano/americano. Agradezco a Lázaro Lima la referencia al trabajo de Christian.

8 En español, intimidad se refiere a una "amistad íntima” y al “conjunto de sentimientos y pensamientos que cada persona guarda en su interior" al mismo tiempo que se utiliza en plural para aludir a las "partes sexuales exteriores del cuerpo del hombre y de la mujer" (Moliner II:159). Esta última acepción sexual del vocablo está ausente en la definición de "intimidad" que se incluye en el $D R A E$ (II:1182), lo que sugiere que se trata de una acepción que ha surgido con el uso. No se debe confundir con privacidad, que viene del inglés "privacy", y que es un término de uso legal que se refiere al "Derecho y propiedad de la propia intimidad y vida privada" (http://www.wordreference. com/definicion/privacidad). 
atrayentes y seductores encarnados por las identidades étnica, sexual y nacional, que compiten y coexisten, para producir un lugar de enunciación inestable, mutable e incómodo, y que se encuentra en un estado de tensión continua con los discursos oficiales sobre la identidad nacional.

\section{INTIMIDADES ALTERNATIVAS EN LA NARRATIVA CARIBEÑA HISPÁNICA MÁS RECIENTE}

En el resto de este ensayo comento tres textos en los que la intimidad queer juega un papel central en la representación de identidades que trascienden los límites tradicionales de la nacionalidad, la otredad étnica y la identidad sexual. El primero de los ejemplos que me interesa comentar es la antología Las historias prohibidas de Marta Veneranda, de Sonia Rivera Valdés publicado primero en Cuba en 1997 y con una segunda edición aumentada que se publicó en Estados Unidos en el año 2000. La colección entera desarrolla lo que Emilio Bejel ha descrito como "an aesthetic of destabilization" por medio de la "representation of the transgression of national, cultural, sexual, and authorial codes" (222), o lo que me gustaría describir como la feminización y ambisexualización de las narrativas del deseo. Con feminización aludo al hecho de que la mayoría de las historias son acerca de mujeres y sus deseos sexuales y personales. Y ambisexualización me permite explorar identidades sexuales que no se identifican necesariamente como heterosexuales, gay o bisexuales, sino que oscilan entre estas varias identificaciones sexuales sin asumir ninguna de ellas como definitoria ni definitiva para estos personajes.

La colección entera se representa como una serie de entrevistas llevadas a cabo por una estudiante graduada, Marta Veneranda, quien está realizando una investigación doctoral sobre las historias "secretas" o "prohibidas" que la gente normalmente no comparte con nadie. Marta desarrolla su proyecto de investigación con el rigor científico de un estudio sociológico, pero muy pronto abandona su entrenamiento doctoral y decide utilizar la ficción como la mejor manera de comunicar y representar los hallazgos de su investigación. La ficción y la fantasía gozan de mayor privilegio que el rigor científico y su concepto de veracidad, y las historias compiladas en esta colección comparten una estructura similar con la confesión católica, la sesión terapeútica y la errancia del chisme entre un grupo de personas, configurando de ese modo una comunidad alternativa que comparte deseos, fantasías y ambigüedades como los motivos centrales de sus historias secretas.

El nombre de Marta Veneranda, por otra parte, nos recuerda etimológica y semánticamente la veneración que se le debe a una figura sagrada, así como la connotación erótica vinculada al placer o la enfermedad "venérea". ${ }^{9}$ De acuerdo con el Diccionario de la Real Academia Española, venerar se define como:

\footnotetext{
9 Agradezco a Ben Sifuentes-Jáuregui esta lectura de las resonancias "venéreas" en el nombre del personaje principal del texto, que elaboró en un “CLAGS Seminar in the City” titulado “Queer@s:
} 
(Del lat. venerari), tr. Respetar en sumo grado a una persona por su santidad, dignidad o grandes virtudes, o a una cosa por lo que representa o recuerda. 2. Dar culto a Dios, a los santos o a las cosas sagradas. (2071)

Venéreo, por otra parte, se define como:

(Del lat. venereus) adj. Perteneciente o relativo a la venus, deleite sexual. 2. Pat. Dícese de la enfermedad contagiosa que ordinariamente se contrae por el trato sexual. (2071)

Por consiguiente, las historias recogidas en este tomo imbrican los placeres prohibidos y ocultos con el carácter divino o virtuoso del sujeto que recopila y reorganiza todos los relatos.

Limitaré mis comentarios a cuatro de los cuentos en la colección -“Cinco ventanas del mismo lado", "Desvaríos”, "La más prohibida de todas” y "El quinto río"- para identificar algunos de los motivos comunes en todas estas narrativas. ${ }^{10}$ Primero, en estos relatos los protagonistas descubren y exploran su otredad sexual, pero en todos los casos el Bildungsroman propuesto por cada narrador culmina en un autodescubrimiento que es temporal, o incluso transitorio, en vez de la resolución definitiva de la interrogante que motiva o desencadena la narración. En "Cinco ventanas", Mayté se involucra con su prima cubana que se encuentra visitando Nueva York como un modo de separarse del marido que la quiere alejar de su segundo hogar, y de su pasado cubano, para empezar una nueva vida en Chicago. Al final de su relato, Mayté no tiene siquiera la certidumbre de que su prima reciproque sus sentimientos, pero la conexión íntima entre las dos mujeres simultáneamente replica y desplaza la identificación nacional cubana. ${ }^{11}$ El narrador de "Desvaríos", Ángel, se identifica públicamente como un hombre gay y construye muy cuidadosamente una vida en la comunidad gay y lésbica, sólo para darse cuenta de que encuentra eróticas e incluso se siente físicamente atraído hacia las mujeres que ve en las películas pornográficas. El secreto en este caso es, pues, el deseo heterosexual, que se encuentra descolocado en el contexto de la vida abiertamente gay del narrador. Sin embargo, en el relato completo, la sexualidad y el deseo se vinculan con la recuperación de las carencias de su infancia marginal y sobreprotegida, pues el narrador se siente atraído por el cuerpo femenino que le

Revisiting Latin(o) American Sexualities” que enseñamos juntos en The Lesbian, Gay, Bisexual \& Transgender Community Center de Nueva York durante la primavera de 2006.

10 En este artículo hago referencia en las citas a las páginas de la edición de 1997 para todos los cuentos, excepto para "El quinto río”, que cito de la edición del año 2000.

${ }^{11}$ Elaboro una lectura más detallada de "Cinco ventanas del mismo lado" y "La más prohibida de todas” en el capítulo seis de mi libro Caribe Two Ways (352-60). 
recuerda a su nana, y por los hombres negros o mulatos que evocan a Sandokan, su amigo de infancia: “Triste de mí, ensombrecido, pasé por la niñez extrañando a Teresita y envidiando a Sandokan” (58).

En “La más prohibida de todas”, Martirio está tratando de encontrar a una pareja que pueda compartir su necesidad de una intimidad que comienza por la palabra y termina en la comunión física. Esta búsqueda comienza con amoríos heterosexuales y se convierte finalmente en su deseo de encontrar a una mujer que pueda ejecutar con ella el libreto sexual que aprendió de sus amantes varones cubanos cuando era joven. El cruce que se propone aquí es interesante, pues Martirio opta por buscar una amante mujer que rearticule el libreto sexual de sus amantes hombres. Sin embargo, una vez que empieza a salir con mujeres, Martirio descubre que el "lesbian continuum” ${ }^{12}$ no es ni mejor ni más simple que la sumisión al orden patriarcal: "He estado con mujeres que afirmaban necesitar más de una relación a la vez porque una sola no les satisfacía sus necesidades. Igualito a los hombres, igualito. Las tuve tan controladoras como Mark, igualitas” (128). Por lo tanto, el relato de Martirio dista mucho de ser una idealización de las relaciones entre mujeres como una solución a la represión patriarcal.

Una de las relaciones que Martirio establece es paralela a la relación íntima entre Marito y Rosita que ya he descrito: Martirio, una mujer bisexual, encuentra el verdadero amor en la relación verbal y sexual que sostiene con Shrinivas, un hombre gay que ocasionalmente se acuesta con mujeres. De acuerdo con Bejel, "the only fulfilling 'heterosexual' love scene in the entire collection occurs between a woman who at one point declares her lesbianism, and a man who describes himself as gay. This is typical of the destabilizing ambiguity that appears throughout those stories and that in 'La más prohibida de todas' is carried to the extreme” (230). Por lo tanto, en esta historia, la bisexualidad o el deseo lésbico representados en su amorío con Rocío son completamente secundarios a la búsqueda de una pareja que pueda satisfacer la necesidad de comunicación física y emocional de Martirio, y la culminación de esa búsqueda es el regreso a Cuba.

Finalmente, en "El quinto río", Catalina quiere confesar su atracción fetichista por el olor de una mujer cuando ésta no se ha bañado en tres días, y su deseo lésbico es un motivo totalmente secundario en su historia. Catalina también recupera su identidad verdadera y más básica cuando decide consumir comida caribeña, en una

\footnotetext{
${ }^{12}$ Aludo aquí, por supuesto, a la noción propuesta por Adrienne Rich en su ensayo fundacional "Compulsory Heterosexuality and Lesbian Existence", y con la que alude a un "range -through each woman's life and throughout history- of women-identified experience; not simply the fact that a woman has had or consciously desired genital sexual experience with another woman” (21). Rivera Valdés se suma a toda una serie de relecturas críticas de este término, que llevan a cuestionar la oposición un tanto binaria entre el lesbian continuum y la heterosexualidad "compulsoria" que predomina en el ensayo de Rich.
} 
escena similar a la que propone Ríos Ávila en su ensayo "Rambling”. El día que decide comer nuevamente "mofongo con chicharrones" en vez de su dieta holística y naturista regular, Catalina se siente reconectada con las pulsiones más básicas de su deseo sexual (158) -haciendo nuevamente eco a la teorización freudiana del vínculo primigenio entre alimentación y sexualidad infantil-y esto desencadena una búsqueda que culmina con su divorcio y su relación con Mayté, la mujer cubana que relata la primera historia secreta en la colección. En todos estos relatos la identidad sexual queer no es la culminación de ninguna de estas "historias secretas", sino un elemento en una narrativa acerca de secretos mucho más profundos en los que la sexualidad se articula como un deseo polimorfo, y no como una pulsión específicamente hetero- u homo-normativa.

Por eso no nos extraña que el segundo elemento que estas historias comparten sea precisamente el subtexto ambisexual (más que bisexual) que permea la mayoría de los relatos. Todas las protagonistas femeninas oscilan entre amantes masculinos y femeninos, y el único protagonista hombre es evidentemente gay, pero canaliza su deseo a través de sus fantasías con amantes femeninas imaginarias que encarnan la figura delamadre/amante experimentada originalmentea través del cuerpo de lanana. ${ }^{13}$ Mayté, Angel, Martirio y Catalina representan sus historias sexuales y emotivas como una búsqueda de un sujeto que comparta los mismos gustos y referentes, y el género sexual de la pareja no es crucial, ni siquiera definitorio, en el modo en que cada uno de estos narradores concibe su propia identidad.

El tercer elemento compartido por la mayoría de estas historias es la representación de la diáspora como una experiencia que distancia al sujeto de la inmediatez de su identificación nacional, permitiendo que el homoerotismo reemplace y se convierta en sinónimo del nacionalismo, entendido como ese amor por el mismo género sexual o referente cultural que promueve el desarrollo de una identidad ectópica (Martínez-San Miguel 350-51). Laura y Rocío, específicamente, funcionan para Mayté y Martirio como pareja sexual y como conciliación con lo cubano, sugiriendo que el nacionalismo se estructura de un modo paralelo al deseo homoerótico. En la diáspora el homoerotismo no es necesariamente el abyecto que se reprime y expulsa del imaginario nacional (Cruz-Malavé 328-29), sino que se convierte en una estructura afectiva y emocional paralela que refuerza e interroga la naturaleza orgánica o esencial de una identidad nacional. En todos los relatos que comento aquí la cubanía reconceptualizada desde la diáspora se convierte en otro espacio en el que la fantasía de una identidad se privilegia por sobre una

\footnotetext{
${ }^{13}$ Este detalle es importante, pues el narrador se siente atraído hacia las mujeres que aparecen en películas pornográficas, pero al momento en que narra su historia secreta, no ha llegado a comprobar su atracción acostándose con una mujer. Por lo tanto, la fantasía prima sobre la experiencia real como una parte vital en la definición de su identidad sexual.
} 
cotidianidad que pospone o interrumpe la vivencia de una identidad nacional sin conflictos. ${ }^{14}$

El próximo texto que me gustaría comentar brevemente es el cuento de Javier Bosco $^{15}$ titulado "Nuestra señora del gozo", que fue incluido en su antología Estriptís y otros despojos, publicada en Puerto Rico en el 2003. ${ }^{16}$ En este cuento el erotismo heterosexual se transforma en una madeja de deseos queer en los que la dimensión corporal de la sexualidad resulta desplazada por las dimensiones mentales o imaginarias de la pasión. De esta manera las tecnologías del género y de la identificación son literalmente rearticulados en una relación personal que es reemplazada por los intercambios telefónicos y electrónicos de una pareja de amantes heterosexuales. Nélida y Sammy se conocen a través del trabajo de ella en una compañía que transmite mensajes a beepers. Nélida es una mujer en sus treinta que no se considera sensual o atractiva, y Sammy le ofrece la primera oportunidad para experimentar placer carnal y sexual real. Desde el comienzo de la narración, el servicio provisto por Celubíper se describe como la expresión de un afecto descorporalizado y mediado:

Adultos, adolescentes y hasta ancianos parecían desechar todo pudor al recurrir a la impersonalidad de un extraño para que transmitiera su elocuencia afectiva; es más, parecían disfrutar con la idea de hacer partícipes de su privacidad a los oídos de un tercero, en una especie de ménage a trois mental que los excitaba más todavía, como si el bíper se transformara en un aparejo de placer añadido a la colección de amaños y adminículos, guardados en la mesita de noche, que servían para llevar la pasión hasta la cumbre. (77)

El relato de Bosco del mundo de deseo creado por medio de las tecnologías de seducción adaptadas para el mundo del beeper, resulta similar a lo que propone Juana María Rodríguez en el capítulo cuatro de Queer Latinidad:

${ }^{14}$ La homosexualidad ha ocupado, histórica y políticamente, un lugar sumamente problemático en el discurso nacional cubano. Frances Negrón Muntaner y yo abordamos este tema y revisamos alguna de la bibliografía más relevante en nuestro artículo y entrevista titulado "En busca de la 'Ana Veldford' de Lourdes Casal: exilio, sexualidad y cubanía”. Remito a los trabajos de Víctor Fowler, Ian Lumsden, Oscar Montero, Brad Epps, Paul Julian Smith y Allen Young citados en la bibliografía.

15 Javier Bosco es el pseudónimo de un escritor boricua que ya ha publicado otros textos narrativos en la isla.

${ }^{16}$ Puerto Rico no tiene todavía una antología de literatura gay, aunque cuenta con una nutrida producción crítica y cultural que aborda el tema de la sexualidad, y tiene una antología de textos relacionados con la epidemia del sida que incluye autores puertorriqueños y se titula POESída (Ed. Carlos A. Rodríguez Matos). Lawrence La Fountain-Stokes, Arnaldo Cruz-Malavé, Rubén Ríos Ávila, Efraín Barradas y Frances Negrón Muntaner, entre otros, han realizado un valioso trabajo de creación de corpus y recuperación de textos en el caso de la cultura boricua tanto insular como en la diáspora. Ver referencias a sus estudios en la bibliografía. 
In cyberspace the schoolgirl, the slave, the rapist has no body; there are no immediate corporeal consequences. Theseidentifications and desires may beexperienced through the body but are not lived through them; this (dis)association can function as part of the erotic charge. McRae writes, "The intensity of pleasure results from the kind of sustained dislocation required when your body is entirely real and entirely imagined at the same time" (261). This dislocation permits an abandonment or expansion of the usual limits of physicality. (137)

La fantasía desplaza la inmediatez concreta del mundo material para privilegiar una realidad virtual. El cuento de Bosco narra, precisamente, el proceso mediante el cual el cuerpo se convierte en una realidad alternativa que depende de otra realidad discursiva que se construye por medio de la ficción:

¿Dónde estás ahora? ¿En mi espalda? ¿En mis caderas? ¿En mis brazos? ¿Trepas por
la escalera de caracol de mi columna vertebral? $\dot{¿}$ Transitas por uno de mis muslos,
como un coágulo asesino camino del corazón? $\dot{¿}$ Te posas sobre mi hombro como
una mano que atrae mi cuerpo para que sea uno con el tuyo? $\dot{¿}$ Giras como un satélite
junto con los planetas que orlan mi cabeza modestamente ladeada? (82). ${ }^{17}$

El giro inesperado de la historia ocurre una noche en la que Sammy prefiere practicar sexo telefónico en vez de participar en una relación sexual física. Nélida no puede entender esta petición, sobre todo porque los dos amantes se encuentran en la misma casa y pueden compartir fácilmente la misma cama. Sin embargo, Sammy prefiere apagar las luces, llamar a Nélida por su teléfono celular, y alcanzar el orgasmo mientras conversa con su amante por teléfono. Nélida se aterra con el comportamiento de Sammy, y comienza a investigar la fascinación de Sammy por un movimiento religioso que idolatra a la Virgen María y que consume todas las energías de los creyentes en un esfuerzo colectivo para reunir fondos con el fin de construir lo que llaman la Ciudad Prístina, que "constaría de una imponente plaza con una imagen de la Virgen del Gozo que mediría 344 pies de altura”, en los que se "albergarían la recepción, una serie de galerías y auditorios, una estación de radio y televisión, un shopping mall con tiendas de comida rápida, ropa y efectos religiosos, dos miradores con vista panorámica, un hotel de 75 habitaciones y, desde luego,

\footnotetext{
${ }^{17}$ Este pasaje tiene ecos del capítulo titulado "Piazza Morgana” de la novela inédita del escritor estadounidense y cubano Calvert Casey. Esta novela fue escrita originalmente en inglés, pero se conserva sólo un capítulo -traducido al español por Vicente Molina Foix- porque Casey destruyó el resto del manuscrito. Los ecos textuales entre estos dos relatos son evidentes, con la diferencia de que Casey narra en primera persona y Bosco en segunda persona: "Ya he entrado en tu corriente sanguínea. He rebasado la orina, el excremento, con su sabor dulce y acre, y al fin me he perdido en los cálidos huecos de tu cuerpo. [...] veo el mundo a través de tus ojos, oigo por tus oídos los sonido más aterradores y los más deliciosos, saboreo todos los sabores con tu lengua, tanteo todas las formas con tus manos". <http://www.lajiribilla.cu/2001/n5_mayo/081_5.html>
} 
una hermosa capilla” (79). El elemento del secreto ya explorado en los cuentos de Rivera Valdés reaparece en estas historias, pero en este caso vinculando el goce al fanatismo religioso como otro modo de canalizar los deseos y pasiones de algunos sujetos. Como parte de esa inversión sexual en su religiosidad, ${ }^{18}$ Sammy gradualmente abandona su vínculo sexual con Nélida para proponerle una relación espiritual y acorporal, como un modo de controlar sus deseos sexuales para cumplir con su compromiso con la Virgen María. En este punto la narración explora el motivo del vínculo entre el deseo sexual como alegoría del goce religioso común en la representación de la etapa unitiva en la poesía mística de San Juan de la Cruz y Santa Teresa de Jesús, pero el relato insiste en los modos en que esa alegoría entra en crisis cuando los dos amantes no comparten las mismas expectativas del vínculo físico y afectivo. ${ }^{19}$ La historia termina con la separación de los amantes, pero lo que resulta interesante es el cambio súbito en el punto de vista narrativo que ocurre en el cierre del cuento. A pesar de que la mayoría del cuento se representa desde la perspectiva de Nélida, en las últimas dos oraciones el narrador invade repentinamente el punto de vista de Sammy, privilegiando su perspectiva para clausurar la historia:

\begin{abstract}
Un día, Nélida descubrió a Sammy en un centro comercial. Estaba sentado ante una mesa plegadiza, vendiendo Mary Cards, rosarios, estampas y pequeñas imágenes de la Virgen del Gozo. Se detuvo frente al tenderete y esperó a que él la reconociera. Sammy la miró con los ojos interrogantes y estuvo un par de minutos atravesando la nube tras la cual, embebida de un fervor místico, flotaba su persona. Nélida, murmuró, pero fue ya muy tarde, porque ella estaba volteando la mesa mientras bailaba un zapateado sobre la mercancía y repetía a gritos: ¡Hipócrita! Sammy sintió un arañazo en el rostro y luego vio, desconcertado, cómo tres guardias de seguridad se la llevaban a rastras. Después se tocó la mejilla y miró su mano: tenía los dedos esmaltados de la sangre que derramó el Redentor. (90-91, énfasis mío)
\end{abstract}

El cuento termina ocupando el mundo fantasioso de los deseos consumados de Sammy, mientras que la "realidad real” de Nélida -expresión que utiliza Juana

\footnotetext{
${ }^{18}$ Utilizo esta frase en el doble sentido de inversión de energías (en inglés investment) y de inversión de la sexualidad (en inglés, sexual inversion), porque el personaje de Sammy fusiona estos dos movimientos.

19 Este es un tema que se elabora en varios de los cuentos de la antología completa, sobre todo en "No hay lugar como el hogar”, "Estriptís” y "Una visita”, donde homoerotismo y religiosidad se presentan a veces como pulsiones complementarias y otras veces como fuerzas contrarias en la articulación de una subjetividad masculina. Puesto que se trata de un texto de muy reciente publicación, hay muy pocos estudios críticos sobre el mismo. Remito al lector, sin embargo, al texto de presentación que se incluye en el libro Los santos torcidos de Javier Bosco, firmado por Santiago Brioso.
} 
María Rodríguez para distinguir la realidad virtual del ciberespacio de la realidad inmediata y material de la vida cotidiana (117) - se descarta en el relato como una locura. En esta subversión de perspectivas de último momento, el relato autoriza los deseos acorporales de Sammy y opta por privilegiar la representación discursiva de su erotismo alternativo. Por otra parte, este pasaje insiste en la referencia a la tradición mística, que, de acuerdo con Michael Horswell, es un discurso alegórico y religioso de la tradición hispánica en el que se populariza el uso de las imágenes homoeróticas que se heterosexualizan más tarde con la poesía de San Juan de la Cruz (Horswell 37-38; 51-55). Por lo tanto, Bosco alude aquí a un momento central de la tradición literaria y cultural hispánica en la que el discurso religioso sirve para oficializar alteridades sexuales que de otro modo no se privilegiaban en géneros de desarrollo paralelo, como la épica o el romance.

El último texto que me interesa comentar es la novela corta de Rey Emmanuel Andújar, El hombre triángulo, publicada primero en Nueva York en 2003 y dos años después en la República Dominicana y Puerto Rico. ${ }^{20}$ Ricardo Piglia ha señalado que "un cuento siempre cuenta dos historias", y que el "relato visible esconde un relato secreto, narrado de un modo elíptico y fragmentario" (92). En el caso de esta novela de Andújar, el relato comienza con el intento de suicidio del teniente Pérez, pero la historia es desviada por la trama más llamativa del arresto de un hombre acusado por correr desnudo en un parque y por el hecho de que el informe de arresto está consignado en un tono lírico inapropiado para un reporte de policía: “cuando nos dirigimos al sujeto, éste cayó como desvanecido, fulminado por el impacto de la aurora" (13). La historia profunda que subyace estos dos eventos inusuales es la compleja exploración de la masculinidad en la sociedad dominicana. ${ }^{21}$ Baraka es el “hombre triángulo”, un poeta, “tecato, sicólogo y científico” (37), quien de inmediato identifica en Pérez una pena muy honda y lo incita a descubrir la fragilidad de su masculinidad, provocando en el teniente un deseo que éste se siente obligado a reprimir y negar. La mayoría del relato aborda la tensión entre “mariconería” y virilidad, entre la naturaleza atormentada de Pérez quien quiere olvidar a su hijo muerto, a su esposa enloquecida y el abuso sexual durante su infancia, y el lirismo desesperado de Baraka,

${ }^{20}$ Cito la edición caribeña en este ensayo. Miguel D. Mena ha escrito la única reseña de esta novela que he podido consultar.

${ }^{21}$ En la República Dominicana la sexualidad queer/LGBT también cuenta con producciones culturales y estudios críticos y culturales, entre los que destaco ensayos de Jacqueline Jiménez Polanco, Yuderkys Espinosa Miñoso, Dulce Reyes Bonilla, E. Antonio de Moya, Andrés L. Mateo, Mark. B. Padilla, y estudios de Carlos Decena y Nelsy Aldebot Reyes. En 2004 se publicó la primera Antología gay dominicana, compilación que generó un intenso debate sobre los problemas de representatividad de un corpus de textos que abordan el tema de la sexualidad, pero no necesariamente desde una perspectiva queer o alternativa. Agradezco a Lawrence LaFountain-Stokes, quien compartió conmigo una “Lista de recursos sobre sexualidad queer/LGBT dominicana” que preparó en julio del 2005. 
un hombre condenado a la errancia y la lejanía. Andújar parece explorar en su relato esa relación simbiótica entre el macho y la loca que Efraín Barradas considera como fundamental para trazar una historia del machismo latinoamericano en su iluminador ensayo "El macho como travestí" (6).

Lo que es interesante de este cuento es que Pérez es incapaz de aceptar su homosexualidad, pero sí está dispuesto a satisfacer algunos de esos deseos reprimidos al establecer una relación más o menos consistente con La Rotunda, una prostituta que se ve bastante masculina, y que como tal ejecuta el rol del amante masculino que Pérez nunca se atreverá a tener:

Rotunda tiene mil razones para llamarse Rotunda: nunca nadie ha visto unas nalgas tan grandes y tan bien formadas y lo que me vuelve loco Rotunda son tus vellos de hombre que nunca te me afeites las piernas Rotunda nunca te me afeites tus bigotitos naturales y tu voz ronca ronquísima desde el fondo más fondo de mis silencios Rotunda tu voz. (26)

Andújar representa el deseo homoerótico por medio del libreto heteronormativo de la relación del macharrán caribeño con la prostituta. Sin embargo, entre ellos se da un espacio alternativo, más allá de lo doméstico y heteronormativo, porque entre ellos las conversaciones post-sexo "son bastante complicadas" (61) y la cama para ellos "ya no era cama, era un campo de batalla, una plaza geométrica donde todas las teorías se caían, rodaban, resbalaban como mangos podridos” (64). Curiosamente, en la novela de Andújar, la prostituta ocupa un lugar afín al que Freud le asigna en sus Three Essays on the Theory of Sexuality, es decir, como aquella que explota la disposición polimorfa o infantil del deseo en sus estrategias de seducción, o la que moviliza una sexualidad que todavía no conoce las regulaciones de la repulsión, la verguenza y la moralidad (57). Por eso no sorprende que al final del relato sea precisamente Rotunda quien ejecuta explícitamente el acto sexual homoerótico que consuma las fantasías del teniente Pérez:

Como mujer buena comprendió todo y reconoció que ya no era cuestión de agotar posiciones, de abrir piernas ni acariciarse las tetas, sacarse la lengua o ponerse en cuatro torpemente. Quizá toda la solución radicaba ahí, con Pérez de espaldas queriendo morirse de pena, de vergüenza del goce que un placer que ahora venía de adentro para afuera, de tres dedos sollozando, rompiendo con la pared dentro de él: Que se me venga el mundo encima, mujeres con faldas largas de luto universal, hombres con botas hasta las rodilla, las lenguas de Baraka, flores con color a muerto, la lejanía, un Triángulo mordiéndome la bemba, ahora que estás tan lejos mi pobre Matilde de niños y guanábanas y esperanzas y tus cicatrices, que será de él en un mundo tan straight. (65, énfasis mío) 
Subversión, intersección y mediación ocurren todas a la vez para posibilitar la consumación de la sexualidad de Pérez más allá de los límites prescritos por la homo- y heterosexualidad. La solución del conflicto de Pérez no está en la escena del abrazo y el beso con Baraka en el bar gay, que sería la culminación de una narrativa homoerótica (45-46), sino en la consumación íntima del deseo que se da gracias a la comprensión de Rotunda en el caso de Pérez, y de Elisa y las habitantes de Danbury, el pueblo pequeño e inusual en el que termina viviendo Baraka. ${ }^{22}$

Propongo que en cada uno de estos textos se implota la relación entre género y sexualidad, deseo e intimidad, en la constitución de un discurso caribeño alternativo sobre las identidades sexuales y étnicas. En los tres casos que he comentado se exploran diferentes dimensiones de la identidad queer, pues en el texto de Rivera Valdés se narrativiza una bisexualidad, lesbianismo y homosexualidad que no encaja en las definiciones ya tradicionales, mientras que los relatos de Bosco y Muñoz, así como el ensayo de Ríos Ávila, abordan una masculinidad que vacila entre el deseo hetero -y homosexual. Incluso en algunos de estos relatos se sugiere que la heterosexualidad misma puede ser profundamente queer si se plantea como parte de un espectro más amplio de deseos que responde a múltiples motivaciones y que se transforma y negocia constantemente.

\section{AmbiSEXUALIDADES: DE VUELTA A LA “REALIDAD REAL”}

Me gustaría concluir este ensayo regresando a la anécdota con la que comencé esta reflexión. Debería empezar por decir que, una vez que se compartió lo que he denominado como el relato de la represión homonormativa-literal en este caso, pues se trata de una drag queen reprimiendo a dos mujeres lesbianas para imponerles una política oficial de la discoteca en cuestión-, el grupo de amigos presentes en esta reunión se enfrascó en un acalorado debate entre los que favorecían y los que rechazaban la política de un bar gay que prohibe que los heterosexuales expresen sus deseos como un modo de crear y proteger un espacio cómodo y seguro para las minorías sexuales. De repente, lo que parecía un grupo de amigos caribeñistas compartiendo unos tragos se transformó nuevamente en un mundo maniqueo obinario en el que los presuntos heterosexuales discutían con los públicamente asumidos como “gays” sobre la naturaleza de la represión y la opresión, argumentando acerca de los efectos reales e inesperados de la prohibición de la libertad sexual como el único modo de producir un espacio alternativo. Algunas personas se fueron a casa justo después de acabada la cena, otras trataron de suavizar tensiones y se quedaron un rato más platicando, y otras se sintieron profundamente ofendidos por lo que

\footnotetext{
${ }^{22}$ Baraka se queda a vivir en un pueblo alternativo, dominado por mujeres y donde su afición a correr
} desnudo se confunde con las prácticas excéntricas de las otras habitantes de la región. 
consideraron como una falta de empatía y solidaridad hacia los efectos todavía prevalecientes de la homofobia en las vidas de aquellos que se definen a sí mismos más allá de un paradigma heteronormativo. Lo que sí resultó evidente fue nuestra incapacidad para contestar ciertas preguntas que superaban nuestros intentos fallidos de comunicación: ¿Cómo podemos crear un espacio alternativo que no replique las mismas estructuras de represión existentes en los discursos e ideologías hegemónicas sobre la identidad sexual? ¿Qué se gana y qué se pierde con la institucionalización de una identidad? ¿Cómo trascender etiquetas identitarias sin volver a invisibilizar y marginar la alteridad sexual? Espero que estas reflexiones literarias puedan servir como un punto de partida para reanudar esta conversación tan difícil que no pudimos concluir en el verano de 2005 en la República Dominicana.

\section{BiBLIOGRAFÍA}

Aldebot Reyes, Nelsy. "Lesbianism as a Form of Women’s Resistance to Patriarchy in the Dominican Republic”. 1991. Artículo inédito.

Andújar, Rey Emmanuel. El hombre triángulo. Nueva York: Essential Icon Press, 2003.

El hombre triángulo. San Juan y Santo Domingo: Isla Negra Editores, 2005.

Barradas, Efraín. "El machismo existencialista de René Marqués: Relecturas y nuevas lecturas”. Sin Nombre 8/3 (San Juan, 1977): 69-81.

Barradas, Efraín. “El macho como travestí: propuesta para una historia del machismo en Puerto Rico”. Fuentes Humanísticas [Revista de la Universidad Autónoma Metropolitana de México]. Próxima aparición, 2006.

Bejel, Emilio. Gay Cuban Nation. Chicago: U of Chicago P, 2001.

Ben, Pablo. "Argentina”. GLBTQ Social Sciences <http://www.glbtq.com/socialsciences/argentina.html $>$ [Consultado el 15 de julio de 2006].

Bosco, Javier. Estriptís y otros despojos. San Juan: Callejón, 2003.

Casey, Calvert. “Piazza Morgana”. <http://www.lajiribilla.cu/2001/n5_mayo/081_5. html> [Consultado el 13 de julio de 2006].

Christian, Karen. Show and Tell: Identity and Performance in US Latin/o Fiction. Albuquerque: New Mexico UP, 1997.

Cruz-Malavé, Arnaldo. “'What a tangled web...!': masculinidad y abyección y la fundación de la literatura puertorriqueña en Estados Unidos”. Revista de crítica literaria latinoamericana 23/45 (primer semestre de 1997): 327-40.

De Moya, E. Antonio. "Power Games and Totalitarian Masculinity in the Dominican Republic”. En Ramírez et al., 105-46. 
Decena, Carlos Ulises. "Queering the Heights: Dominican Transnational Identities and Male Homosexuality in New York City”. Ph.D. diss., New York University, 2004.

Dopico, Ana María. "Cubanologies: Patriotic Aesthetics, Visual Imaginaries and the Dialectics of National Culture”. Manuscrito de libro inédito.

Duggan, Lisa. "The New Homonormativity: The Sexual Politics of Neoliberalism". Materializing Democracy: Toward a Revitalized Cultural Politics. Russ Castronovo y Dana D. Nelson, eds. Durham: Duke UP, 2002.

Epps, Brad. "Proper Conduct: Reinaldo Arenas, Fidel Castro, and the Politics of Homosexuality”. Journal of the History of Sexuality 6/2(1995): 231-283.

Espinosa Miñoso, Yuderkys. "Homogeneidad, proyecto de nación y homofobia". En Torres-Saillant et al., 361-368.

Fowler, Víctor. “Homoerotismo y construcción de la nación”. La gaceta de Cuba 1/36 (enero-febrero 1998): 2-6.

La maldición: una historia del placer como conquista. La Habana: Editorial Letras Cubanas, 1998.

Freud, Sigmund. Three Essays on the Theory of Sexuality [1905]. James Strachey, trad. Cambridge: Basic Books, 2000.

Gallop, Jane. Anecdotal Theory. Durham: Duke UP, 2002.

García, Mélida and Miguel de Camps Jiménez, eds. Antología de la literatura gay en la República Dominicana. Santo Domingo: Editora Manatí, 2004.

Jiménez Polanco, Jacqueline. "The Lesbian, Gay, Bisexual, Trans, and Queer (LGBTQ) Movement in the Dominican Republic: A Sociopolitical and Cultural Approach”. <http://www.globalgayz.com/domrep-JP-news.html> [Consultado el 10 de julio de 2006].

LaFountain-Stokes, Lawrence. "Queer Ricans: Cultures and Sexualities in the Diaspora”. Manuscrito de libro inédito.

Lima, Lázaro. Latino Bodies: Crisis Identities in American Literary and Cultural Memory. Nueva York: New York UP, 2007.

Lumsden, Ian. Machos, Maricones, and Gays: Cuba and Homosexuality. Filadelfia: Temple UP, 1996.

Martínez-San Miguel, Yolanda. Caribe Two Ways: cultura de la migración en el Caribe insular hispánico. San Juan: Ediciones Callejón, 2003.

y Frances Negrón Muntaner. "En busca de la 'Ana Veldford' de Lourdes Casal: exilio, sexualidad y cubanía”. Debate feminista 17/33 (abril 2006): 166-197.

Mateo, Andrés L. “La poesía homosexual dominicana”. Al filo de la dominicanidad. Santo Domingo: Librería la Trinitaria, 1996. 
Mena, Miguel D. “Geometría para otra isla: 'El hombre triángulo’, de Rey Emanuel Andújar”. Letras Dominicanas. <http://www.cielonaranja. com/2006menaandujar.htm> [Consultado el 20 de junio de 2006].

Moliner, María. Diccionario de uso del español. Madrid: Gredos, 1992.

Montero, Oscar. “Julián del Casal and the Queers of Havana”. ¿Entiendes? Queer Readings, Hispanic Writings. Emilie Bergmann y Paul Julian Smith, eds. Durham: Duke UP, 1995. 92-112.

Muñoz, Elías Miguel. The Greatest Performance. Houston: Arte Publico Press, 1991.

Negrón-Muntaner, Frances. Boricua Pop. Puerto Ricans and the Latinization of American Culture. Nueva York: New York UP, 2004.

y Ramón Grosfoguel. Puerto Rican Jam: Rethinking Colonialism and Nationalism. Minneapolis: U of Minnesota P, 1997.

Padilla, Mark B. "Ethnographic Reflections on the First Pride March in Santo Domingo, Dominican Republic”. En Ramírez, et al., 173-179.

Piglia, Ricardo. Formas breves. Buenos Aires: Tema Grupo Editorial, 1999.

Quiroga, José. Cuban Palimpsests. Minneapolis: The U of Minnesota P, 2005. Tropics of Desire: Interventions from Queer Latino America. Nueva York: New York UP, 2001.

Ramírez, Rafael, Víctor García-Toro e Ineke Cunningham, eds. Caribbean Masculinities: Working Papers. San Juan: Centro de Investigación y Educación en VIH/SIDA, Universidad de Puerto Rico, 2002.

Reyes Bonilla, Dulce. "Primero puta que pájara: Sexuality and Dominicanness". En Torres-Saillant et al., 369-382.

Rich, Adrienne. Compulsory Heterosexuality and Lesbian Existence. Londres: Onlywomen Press, 1981.

Ríos Avila, Rubén. "Rambling”. La raza cómica del sujeto en Puerto Rico. San Juan: Ediciones Callejón, 2002. 311-318.

Rivera Valdés, Sonia. Las historias prohibidas de Marta Veneranda. La Habana: Ministerio de Cultura de Colombia y Casa de Las Américas, 1997.

Las historias prohibidas de Marta Veneranda. Segunda edición. Nueva York: Siete Cuentos Press, 2000.

Rodríguez, Juana María. Queer Latinidad: Identity Practices, Discursive Spaces. Nueva York: New York UP, 2003.

Rodríguez Matos, Carlos A., ed. POESída. Nueva York: Ollantay Press, 1995.

Smith, Paul Julian. "Cuban Homosexualities: On the Beach with Néstor Almendros and Reinaldo Arenas". Hispanisms and Homosexualities. Sylvia Molloy y Robert McKee Irwin, eds. Durham: Duke UP, 1998. 248-268. 
Torres-Saillant, Silvio, Ramona Hernández, y Blas Jiménez, eds. Desde la orilla: hacia una nacionalidad sin desalojos. Santo Domingo: Editora Manatí, Ediciones Librería La Trinitaria, 2004.

Young, Allen. Gays Under the Cuban Revolution. San Francisco: Grey Fox Press, 1981. 
